F. Reprod. Fert. (1966) 12, 369-372

BRIEF COMMUNICATION

\title{
TENTATIVE IDENTIFICATION OF PLASMA, OVARIAN AND PLACENTAL OESTROGENS IN THE GUINEA-PIG*
}

\author{
R. L. GHURCH AND B. E. ELEFTHERIOU \\ Department of Zoology, Kansas State University, \\ Manhatten, Kansas, U.S.A.
}

(Received 20th December 1965, revised 24th April 1966)

Following development of more accurate and sensitive chemical and physical identification techniques for oestrogen determinations, many species have been studied. Since 1955 oestrogenic steroids have been identified in at least twentyfive species of animals. In our laboratory, the dog (Metzler, Eleftheriou \& Fox, 1966), the channel catfish (Eleftheriou, Boehlke \& Tiemeier, 1966a) and the deer (Eleftheriou, Boehlke, Zolovick \& Knowlton, 1966b) have been studied.

The oestrogen picture has been notably inconsistent as to types of oestrogens produced in various species and to quantitative levels maintained in the blood, ovary and placenta. Although oestradiol-17 $\beta$ seems to be the major oestrogen in most of the species examined, there is no observed pattern in either oestrogen types or levels of circulating oestrogen metabolites in the blood within the animal kingdom. Studies reported here attempted to identify the oestrogens in the plasma, ovary and placenta of the laboratory guinea-pig and to quantitate these oestrogens using a fluorometric technique.

Eighty adult female guinea-pigs, weighing from 440 to $1060 \mathrm{~g}$ and averaging $649 \mathrm{~g}$, were separated into two groups of normal cycling and pregnant animals. Blood was obtained by decapitation, heparinized and centrifuged at $1000 \mathrm{~g}$ to separate the plasma, which was frozen for later steroid analysis. Ovaries and placentae were collected, weighed and frozen.

Several $100-\mathrm{ml}$ aliquots of the plasma, 7-g aliquots of ovarian homogenate and 30-g aliquots of placental homogenate were extracted by shaking three times with 2 volumes of anhydrous ether. The residue was then made up to $20 \%$ with $\mathrm{H}_{2} \mathrm{SO}_{4}$ and refluxed for $24 \mathrm{hr}$. All ether extracts from one aliquot were pooled and taken to dryness in vacuo at $37^{\circ} \mathrm{C}$. Further purification and chromatography was followed exactly as described (Eleftheriou et al., 1966a).

Straight chromatography and simultaneous chromatography with the unknown and standard oestrogens on one origin, followed by spraying the plates with an ethanolic $10 \%$ phosphomolybdic acid solution to visualize the spots,

*Contribution No. 365 from the Department of Zoology, Kansas Agricultural Experiment Station, Manhattan, Kansas, U.S.A. 


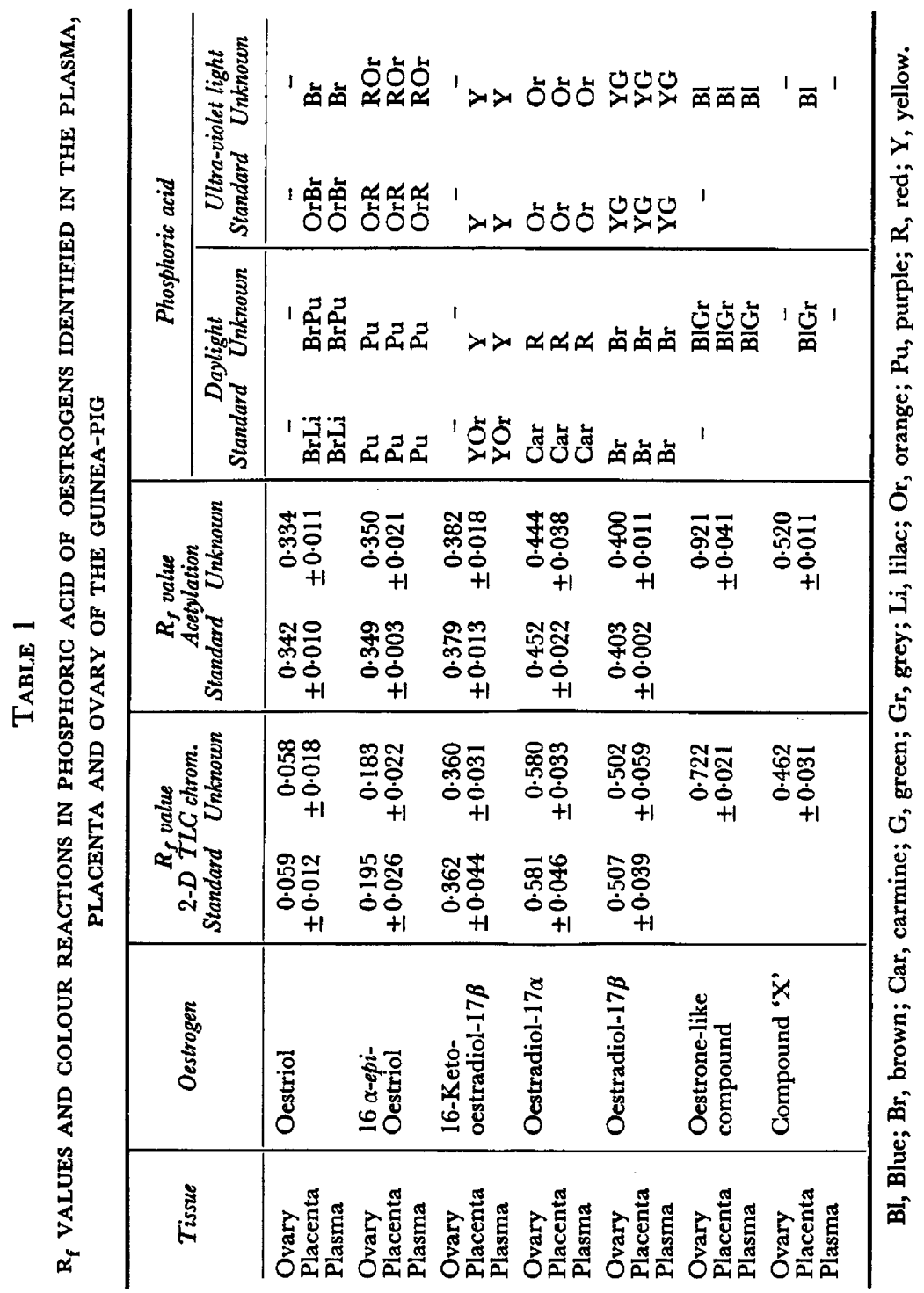


indicated five and sometimes six spots corresponding with standard oestriol, $16 \alpha$-epioestriol, oestradiol-17 $\alpha$, oestradiol- $17 \beta$, oestrone, and sometimes 16-ketooestradiol-17 $\beta$. Other unknown and standard chromatograms, which were developed and sprayed with phosphoric acid to observe colour reactions (Lisboa \& Diczfalusy, 1963), showed five spots in the plasma corresponding to oestriol, 16 $\alpha$-epioestriol, oestradiol-17 $\alpha$, oestradiol-17 $\beta$, oestrone and a spot with mobility between 16 -keto-oestradiol-17 $\beta$ and oestradiol-17 $\beta$ which may have been 2-hydroxyoestradiol. Further viewing under ultra-violet light following phosphoric acid spraying showed that the spot corresponding to oestrone was not oestrone. 2-Methoxyoestrone, which has essentially an identical mobility with oestrone, was compared to the unknown oestrone-like spot with negative results. Possibly this oestrogen was $16 \alpha$-hydroxyoestrone or 16-oxo-oestrone. Acetylation (Bush, 1960) by the slow method was carried out on the placenta, ovaries and plasma. After the chromatograms were developed, the plates were sprayed with phosphomolybdic acid to visualize the acetylated compounds. This procedure gave spots that corresponded to oestriol, 16 $\alpha$-epioestriol, 16-ketooestradiol-17 $\beta$, oestradiol-17 $\alpha$, and oestradiol-17 $\beta$ in the plasma, the same oestrogens in the placenta, and oestradiol-17 $\alpha$, oestradiol-17 $\beta$ and 16-epioestriol in the ovaries. Table 1 shows $R_{\mathrm{f}}$ values for unsubstituted and acetylated oestrogens as well as colour reactions with phosphoric acid for standard and unknown oestrogens.

On the basis of chromatography, simultaneous chromatography, acetylation, and colour reactions with phosphomolybdic acid and phosphoric acid (Lisboa \& Diczfalusy, 1963), the oestrogens of the guinea-pig plasma were tentatively identified as oestriol, 16 $\alpha$-epioestriol, 16-keto-oestradiol-17 $\beta$ and oestradiol-17 $\alpha$, oestradiol-17 $\beta$, and an oestrone-like compound. The placenta contained the same oestrogens and one other oestrogen, perhaps hydroxyoestradiol. Ovarian oestrogens were identified as oestradiol-17 $\alpha$, oestradiol-17 $\beta, 16 \alpha$-epioestriol and the oestrone-like substance.

Ratios of the oestrogens were obtained in the plasma, placenta and ovary using sulphuric acid fluorescence (Eleftheriou et al., 1966b). In the plasma of the pregnant guinea-pig the oestrogen levels in $\mu \mathrm{g} / 100 \mathrm{ml}$ were: oestriol, 0.35 ; oestradiol- $17 \alpha, 0.64$; oestradiol-17 $\beta, 0.67 ; 16$-keto-oestradiol-17 $\beta, 1.71$; oestrone-like compound, $2 \cdot 86$; and 16 $\alpha$-epioestriol, $3 \cdot 25$. Ovarian oestrogen levels in $\mu \mathrm{g} / 100 \mathrm{mg}$ tissue were: oestradiol-17 $\beta, 0.0004$; oestradiol-17 $\alpha, 0.013$; $16 \alpha$-epioestriol, 0.013 ; and the oestrone-like compound, 0.017 . The placental oestrogen levels in $\mu \mathrm{g} / 100 \mathrm{mg}$ were: oestradiol-17 $\beta, 0.22$; oestriol, 0.39 ; oestradiol-17 $\alpha, 0.67 ; 16 \alpha$-epioestriol, $1.65 ; 16$-keto-oestradiol-17 $\beta, 1.76$; and the oestrone-like compound, $4 \cdot 85$.

Other oestrogen metabolites probably are present in guinea-pigs, especially pregnant ones, but at levels too low to be detected. It appears that the placenta has a higher concentration of oestrogens than the ovary and that during pregnancy more types of oestrogens are being formed and metabolized.

This research was supported by special Grant No. 663 from the Kansas Agricultural Experiment Station. 


\section{REFERENCES}

Bush, I. E. (1961) The chromatography of steroids, Vol. 2, p. 358. Macmillan, New York.

Eleftheriou, B. E., Boehlke, K. W. \& Tiemeier, O. W. (1966a) Free plasma estrogens in the channel catfish. Proc. Soc. exp. Biol. Med. 121, 85.

Eleftheriou, B. E., Boehlke, K. W., Zolovick, A. \& Knowlton, F. (1966b) Free plasma estrogens in the deer. Proc. Soc. exp. Biol. Med. 121, 88.

Lisboa, B. P. \& Diczfalusy, E. (1963) Colour reactions for the in situ characterisation of steroid oestrogens on thin-layer chromatograms. Acta endocr., Copenh. 43, 545.

Metzler, F., Eleftheriou, B. E. \& Fox, M. (1966) Quantitative estimation of free plasma oestrogens in the dog during the estrous cycle and pregnancy. Proc. Soc. exp. Biol. Med. 121, 374. 